\title{
Adsorption mechanism of poly(vinyl alcohol) on the surfaces of synthetic zeolites: sodalite, Na-P1 and Na-A
}

\author{
Małgorzata Wiśniewska' ${ }^{1}$ (D) Gracja Fijałkowska ${ }^{1} \cdot$ Agnieszka Nosal-Wiercińska $^{2} \cdot$ Małgorzata Franus $^{3} \cdot$ Rafał Panek $^{3}$
}

Received: 28 December 2018 / Revised: 14 February 2019 / Accepted: 22 February 2019 / Published online: 7 March 2019

(c) The Author(s) 2019

\begin{abstract}
The structure of poly(vinyl alcohol)_PVA layers adsorbed on the synthetic zeolites surfaces was determined. Three zeolites: sodalite, Na-P1 and Na-A were obtained using hydrothermal conversion of fly ash with aqueous sodium hydroxide. The effects of solution $\mathrm{pH}$ and zeolite type on the adsorption mechanism of the polymer were examined. The analysis of the results obtained by means of spectrophotometric and microelectrophoretic measurements as well as potentiometric titrations enabled description of interfacial behaviour of adsorbed macromolecules. It was shown that the presence of poly(vinyl alcohol) layers modifies the surface properties of applied zeolites. The evidence of this are changes in the surface charge density and zeta potential of solid particles observed in the polymer presence. Moreover the PVA chains exhibit different adsorption affinity for the examined zeolites depending mainly on the mean pore size of these aluminosilicates which is very important for penetration of internal zeolite structure by polymeric macromolecules.
\end{abstract}

Keywords Synthetic zeolite $\cdot$ Poly(vinyl alcohol) adsorption · Sodalite $\cdot$ Electrokinetic properties $\cdot$ Electrical double layer . Surface properties modification

\section{Introduction}

The basic criterion for the classification of adsorbents is their specific surface, precisely their size and structure. There are porous and non-porous adsorbents. Porous adsorbents are characterized by better sorption properties due to the relatively well-developed surface area of up to hundreds or thousands of $\mathrm{m}^{2} / \mathrm{g}$, and consequently, they have great sorption capacity and high adsorption efficiency. The main representatives of this group are silica gels, activated

Małgorzata Wiśniewska

wisniewska@hektor.umcs.lublin.pl

1 Department of Radiochemistry and Colloids Chemistry, Faculty of Chemistry, Maria Curie-Sklodowska University, M. Curie-Sklodowska Sq. 3, 20-031 Lublin, Poland

2 Department of Analytical Chemistry and Instrumental Analysis, Faculty of Chemistry, Maria Curie-Sklodowska University, M. Curie-Sklodowska Sq. 3, 20-031 Lublin, Poland

3 Department of Geotechnics, Civil Engineering and Architecture Faculty, Lublin University of Technology, Nadbystrzycka Street 40, 20-618 Lublin, Poland carbons, aluminum oxides and zeolites which are widely applied in various branches of industry.

Zeolites have a porous structure that can accommodate a wide variety of cations. They have a crystalline structure and mainly consist of silicon, aluminium, oxygen and metals such as zinc and titanium. The silicon and aluminium atoms are tetrahedrally coordinated with each other through the shared oxygen atoms so aluminosilicate minerals are made of interlinked tetrahedrons of alumina $\left(\mathrm{AlO}_{4}\right)$ and silica $\left(\mathrm{SiO}_{4}\right)$. These three dimensional microporous solids have a well-developed network of interconnected pores and tunnels of different sizes which can be filled with the so-called "zeolite water". In addition, besides water molecules alkali metal cations are present in the network of channels. The cations are loosely held and can be exchanged for others in a contact solution. As a result, zeolites exhibit ion exchange capacity, i.e. they can adsorb specific ions and molecules. They are characterized by sorption properties and can be used as molecular sieves. Zeolites have the ability to sort molecules selectively based on a size exclusion process. This is due to a very regular pore structure of molecular dimension (Panek et al. 2017; Woszczuk and Franus 2017; Bandura et al. 2017; Franus et al. 2015). 
The cage-like structure of zeolites makes them useful in all sorts of ways. One of the greatest everyday uses of zeolites is in water softeners and water filters. In the ionexchange process zeolites release sodium ions trapping the calcium and magnesium ones. Zeolites are widely used as filters in domestic and commercial water purification. In chemistry they employed to separate molecules of specific sizes and accommodate them so they can be analysed. Zeolites are also popular ingredients of detergents, washing powders and toothpastes. The other application of zeolites is as catalysts because their internal structure and adjustable acidity make them highly active in a large variety of reactions such as cracking or hydrocracking. Synthetic zeolites are employed as the additive in the production of warm mixed asphalt concrete. The porous crystalline structure is helpful by trapping molecules, for example radioactive particles from nuclear wastes, toxic heavy metals and odour molecules. This type of adsorbents can be used as an additive for soil treatment due to their hydroscopic properties. It provides a source of slowly released potassium or nitrogen. Zeolites can also act as water moderators in which they will absorb water and slowly release it according to the plant demand. In medicine zeolites can be used in production of surgery materials and tools. This type of adsorbents can accommodate silver ions of antiseptic and antibacterial properties (Derkowski et al. 2006; Querol et al. 2002; Franus and Wdowin 2010, 2011; Kyziol-Komosińska et al. 2015; Sprynskyy et al. 2005; Bandura et al. 2017; Chałupnik et al. 2013; Wdowin et al. 2012; Franczyk and Garbulewski 2013).

Zeolites occur naturally, however, they are fabricated commercially on a huge scale (Kunecki et al. 2017; Woszczuk and Franus 2017; Franus et al. 2014, 2015; Bandura et al. 2016). Synthetic zeolites are manufactured by heating the aqueous solution of alumina and silica with sodium hydroxide (so-called hydrothermal method of zeolites synthesis). Owning to this method it is possible to produce structures that do not appear in nature. Moreover, the natural zeolites exhibit worse sorption and catalytic properties than the synthetic ones. Nevertheless, there are methods for modifying zeolites which enchance their ion exchange, sorption capacity and as a result, a more selective sorbent is obtained (Zhang et al. 2015; Musyoka et al. 2014; Bukhari et al. 2015; Bandura et al. 2017).

Thus the main aim of this paper was modification of the surface area of the synthetic zeolites by the adsorption of poly(vinyl alcohol) which contributes to changes in their electrokinetic and surface properties. The effects of solution $\mathrm{pH}$ and internal structure of the zeolites were also studied. Using spectrophotometry, potentiometric titration and microelectrophoresis methods the adsorption and electrokinetic properties of the synthetic zeolties-PVA systems were examined. Additionally, the examined zeolites (sodalite, Na-P1 and Na-A) were obtained from fly ash, originating from conventional coal combustion. In this way, the hazardous waste material has been transformed into an effective sorbent which can be re-used for various practical applications.

\section{Experimental}

\subsection{Materials and their characteristics}

The samples of three synthetic zeolites (sodalite, Na-P1 and $\mathrm{Na}-\mathrm{A}$ ) were prepared on a quarter-technical scale using a prototype installation for the synthesis of zeolites from fly ash located at the Lublin University of Technology. All zeolites were obtained by the hydrothermal conversion of fly ash with aqueous sodium hydroxide according to the following reaction:

$$
\text { flyash }+\mathrm{NaOH} \underset{\text { temperature }}{\rightarrow} \text { zeolite }+ \text { ashresidue }
$$

Fly ash originated from conventional coal combustion. The aluminosilicate glaze present in the fly ash is a carrier of aluminium and silicon, i.e. the elements necessary for the zeolite structure building. On the other hand, Na came from sodium hydroxide which was a sodium carrier and dissolved the aluminosilicate phase in fly ash.

Using appropriate reaction parameters such as temperature, time, substrate concentration, zeolite materials containing the zeolite phases: sodalite, $\mathrm{Na}-\mathrm{P} 1$ and $\mathrm{Na}-\mathrm{A}$ as well as unreacted ash residue (consisting mainly of mullite and quartz) were obtained (Wdowin et al. 2014).

Textural parameters of the examined zeolites were determined by the BET method (ASAP 2020 analyzer, Micromeritics Instrument Corporation). The adsorption/desorption isotherms of nitrogen vapour were measured at the temperature of liquid nitrogen $(77 \mathrm{~K})$ for the relative pressures $\mathrm{p} /$ $\mathrm{p}_{0}$ changing from $1.7 \cdot 10^{-7}$ to 0.991 . Elemental composition of zeolites was determined using the XRF technique (Panalytical ED-XRF type Epsilon 3 spectrometer). These studies were performed in the $\mathrm{Na}-\mathrm{Am}$ range using the apparatus equipped with the RTG tube Rh $9 \mathrm{~W}$ (X-ray energy $50 \mathrm{kV}$ ). Moreover, the SEM imaging (FEI Quanta 250 FEG) was used for the determination of surface morphology of the examined zeolites.

Poly(vinyl alcohol)_PVA with the molecular weight of $100,000 \mathrm{Da}$ and the hydrolysis degree $86 \%$ was used for modification of zeolite surface properties. Besides the hydroxyl groups (of nonionic character) this macromolecular compound contains $14 \%$ of the acetate ones (residue after incomplete hydrolysis of polyvinyl acetate). These groups are the source of negative charge of polymeric chains 
(Wiśniewska et al. 2016). The mechanism of this charge creation is as follows:
$-0.41 \mathrm{~g}, \mathrm{Na}-\mathrm{P} 1-0.25 \mathrm{~g}$ and $\mathrm{Na}-\mathrm{A}-0.17 \mathrm{~g}$. The measuring set was composed of the following parts: burette Dosimat

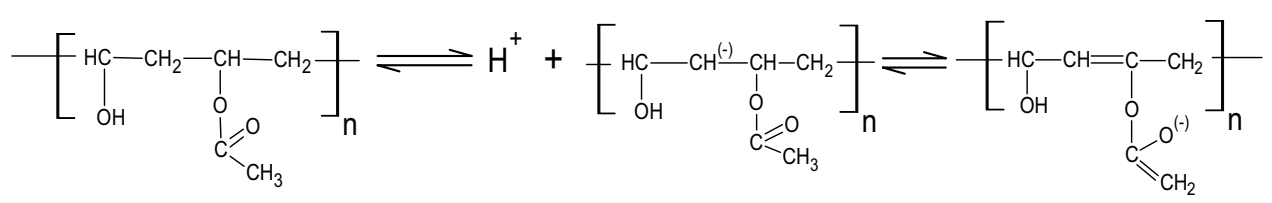

Additionally, the zeta potential measurements (Zetasizer Nano ZS, Malvern Instruments) performed for PVA solution of the concentration $100 \mathrm{ppm}$ within the $\mathrm{pH}$ range 3-9 proved that poly(vinyl alcohol) macromolecules are endowed with the slight negative charge (Table 1).

The adsorption measurements were performed at $25^{\circ} \mathrm{C}$ using the static method. For this purpose $1 \mathrm{~g}$ of the solid was introduced to $10 \mathrm{~mL}$ of each sample of polymer solution. These samples differed in the initial concentrations $(50,70,100$ or $200 \mathrm{ppm})$ and $\mathrm{pH}$ values $(3,6$ or $9 \pm 0.1)$. The adsorption process was conducted out under the conditions of continuous shaking (water bath OLS 200, Grant) for $24 \mathrm{~h}$. After this time the solids were centrifuged using a microcentrifuge (MPW Med. Instruments). The clear polymer solutions were subjected to further analysis of polymer concentration. The difference between the PVA concentrations in the solutions before and after the adsorption process was used for the polymer adsorbed amount calculation. The PVA reaction with $\mathrm{H}_{3} \mathrm{BO}_{3}$ and $\mathrm{I}_{2}$ solutions (Zwick 1965) was applied for poly(vinyl alcohol) concentration determination and calibration curve preparation. As a result, green colour of polymeric solution with different intensities (depending on the PVA concentration) was obtained. The corresponding absorbance was measured spectrophotometrically at the wavelength $682 \mathrm{~nm}$ (UV/VIS spectrophotometer Cary 100, Varian).

The surface charge density $\left(\sigma_{0}\right)$ as a function of solution $\mathrm{pH}$ and point of zero charge (pzc) of the examined zeolites were determined applying the potentiometric titration method (Janusz 1994). The potentiometric titrations of zeolite suspensions without and with PVA (with the concentration of $100 \mathrm{ppm}$ ) were performed in the thermostated Teflon vessel using the following mass of the solids: sodalite

Table 1 Zeta potential of PVA macromolecules in aqueous solution at different solution $\mathrm{pH}$ values; $\mathrm{C}_{\mathrm{PVA}} 100 \mathrm{ppm}$

\begin{tabular}{ll}
\hline $\mathrm{pH}$ value & Zeta potential $[\mathrm{mV}]$ \\
\hline 3 & -0.662 \\
4 & -2.552 \\
5 & -3.975 \\
6 & -4.123 \\
7 & -4.465 \\
8 & -4.625 \\
9 & -4.767 \\
\hline
\end{tabular}

665 (Methrom), thermostat RE204 (Lauda), pH meter 71 (Beckman), computer and printer. The solid surface charge density was calculated with the special program Titr_v3 (authored by W. Janusz) using the following equation:

$\sigma_{0}=\frac{\Delta V \cdot c \cdot F}{m \cdot S}$

where $\Delta V$ - the difference in the base volume added to the suspension and the reference solution that leads to the specific $\mathrm{pH}$ value, $c$ - the base concentration, $F$-the Faraday constant, $m$ - the solid mass in the suspension, $S$ - the solid surface area.

The examined systems were titrated by the $\mathrm{NaOH}$ solution with the concentration of $0.1 \mathrm{~mol} / \mathrm{L}$. At the beginning the reference curve was obtained (for water without zeolite).

The electrophoretic mobility $\left(\mathrm{U}_{\mathrm{e}}\right)$ of the examined zeolite suspensions was measured in the systems without and with PVA (with the concentration of $100 \mathrm{ppm}$ ) using Zetasizer Nano ZS (Malvern Instruments). The suspensions were prepared adding $0.01 \mathrm{~g}$ of the solid to $150 \mathrm{~mL}$ of the water or polymer solution. After the suspension sonication (ultrasonicator XL 2020, Misonix), the solution was divided into 7 parts, each of $20 \mathrm{~mL}$ volume. Then the appropriate $\mathrm{pH}$ value $(3,4,5,6,7,8$ and $9 \pm 0.1)$ was adjusted using a $\mathrm{pH}$ meter (Beckman Instruments). Electrophoretic mobility of solid particles dispersed in the liquid medium was measured using the dip cell (five repetitions of measurements for each sample) (Gun'ko et al. 2003). The zeta potential ( $\zeta$ ) was calculated with the special computer program using the Henry equation (Hunter 1981):

$U_{e}=\frac{2 \varepsilon_{0} \varepsilon \zeta}{3 \eta} f(\kappa a)$

where $\varepsilon$ - the dielectric constant, $\varepsilon_{0}$-the electric permeability of vacuum, $\eta$ — the viscosity of liquid medium, $f(\kappa)$ - the Henry function.

\section{Results and discussion}

The textural and elemental composition characteristics of the examined zeolites is presented in Table 2. As can be seen Na-A zeolite possesses the largest BET surface area has (about $74.2 \mathrm{~m}^{2} / \mathrm{g}$ ). In the case of this solid the 
Table 2 Applied zeolites characteristics

\begin{tabular}{|c|c|c|c|}
\hline & Sodalite & $\mathrm{Na}-\mathrm{P} 1$ & $\mathrm{Na}-\mathrm{A}$ \\
\hline \multicolumn{4}{|l|}{ Textural parameters } \\
\hline BET surface area $\left[\mathrm{m}^{2} / \mathrm{g}\right]$ & 53.64 & 47.1 & 74.16 \\
\hline Micropore area $\left[\mathrm{m}^{2} / \mathrm{g}\right]$ & 28.73 & 8.39 & 47.24 \\
\hline Pore volume $\left[\mathrm{cm}^{3} / \mathrm{g}\right]$ & 0.234 & 0.105 & 0.136 \\
\hline Micropore volume $\left[\mathrm{cm}^{3} / \mathrm{g}\right]$ & 0.013 & 0.004 & 0.024 \\
\hline Mean pore diameter $[\mathrm{nm}]$ & 17.5 & 8.95 & 7.33 \\
\hline \multicolumn{4}{|l|}{ Elemental composition [\%] } \\
\hline $\mathrm{Na}_{2} \mathrm{O}$ & 14.072 & 4.573 & 3.225 \\
\hline $\mathrm{MgO}$ & 2.341 & 1.616 & 2.022 \\
\hline $\mathrm{Al}_{2} \mathrm{O}_{3}$ & 24.089 & 29.663 & 26.234 \\
\hline $\mathrm{SiO}_{2}$ & 40.377 & 46.918 & 51.177 \\
\hline $\mathrm{P}_{2} \mathrm{O}_{5}$ & 0.08 & 0.279 & 0.216 \\
\hline $\mathrm{SO}_{3}$ & 0.063 & 0.037 & 0.041 \\
\hline $\mathrm{K}_{2} \mathrm{O}$ & 4.14 & 0.77 & 2.326 \\
\hline $\mathrm{CaO}$ & 0.091 & 3.118 & 3.812 \\
\hline $\mathrm{TiO}_{2}$ & 4.198 & 1.968 & 1.412 \\
\hline $\mathrm{Cr}_{2} \mathrm{O}_{3}$ & 1.397 & 0.052 & 0.049 \\
\hline $\mathrm{MnO}$ & 0.047 & 0.07 & 0.105 \\
\hline $\mathrm{Fe}_{2} \mathrm{O}_{3}$ & 0.104 & 10.287 & 8.987 \\
\hline $\mathrm{Co}_{3} \mathrm{O}_{4}$ & 8.668 & 0.065 & 0.052 \\
\hline $\mathrm{NiO}$ & 0.05 & 0.04 & 0.028 \\
\hline $\mathrm{CuO}$ & 0.028 & 0.031 & 0.022 \\
\hline $\mathrm{ZnO}$ & 0.019 & 0.03 & 0.028 \\
\hline $\mathrm{SrO}$ & 0.023 & 0.204 & 0.014 \\
\hline $\mathrm{ZrO}_{2}$ & 0.077 & 0.081 & 0.067 \\
\hline $\mathrm{Ag}_{2} \mathrm{O}$ & 0.032 & 0.096 & 0.037 \\
\hline $\mathrm{BaO}$ & 0.056 & 0.089 & 0.074 \\
\hline $\mathrm{PbO}$ & $0.04 \mathrm{ppm}$ & 0.014 & 0.054 \\
\hline
\end{tabular}

micropore area is also the largest (about $47.2 \mathrm{~m}^{2} / \mathrm{g}$ ). Moreover, the mean pore diameter is the lowest for Na-A zeolite (about $7.3 \mathrm{~nm}$ ) of all applied solids. On the other hand, sodalite is characterized by the largest mean pore diameter $(17.5 \mathrm{~nm})$. The pore size is very important for adsorption of large macromolecules such as poly(vinyl alcohol) chains due to limited possibilities of their penetration into the solid internal structure. Such mechanism is highly probable because the radius of gyration for PVA molecules with weight average molecular weight equal to $100,000 \mathrm{Da}$ is about $15 \mathrm{~nm}$ (Nagy 2004). Analyzing the elemental composition of the applied zeolites, it should be noted that $\mathrm{Na}-\mathrm{A}$ zeolite has the highest $\mathrm{Si} / \mathrm{Al}$ ratio. On the other hand, sodalite contains in their structure the greatest amount of $\mathrm{Na}^{+}$and $\mathrm{K}^{+}$exchangeable cations. In turn, $\mathrm{Na}-\mathrm{P} 1$ zeolite is characterized by the greatest content of $\mathrm{Fe}_{2} \mathrm{O}_{3}$ of all examined solids. The SEM images of zeolites are presented in Fig. 1. The Na-A zeolite particles form aggregates of large sizes. In the case of sodalite and Na-P1 these structures are significantly smaller.
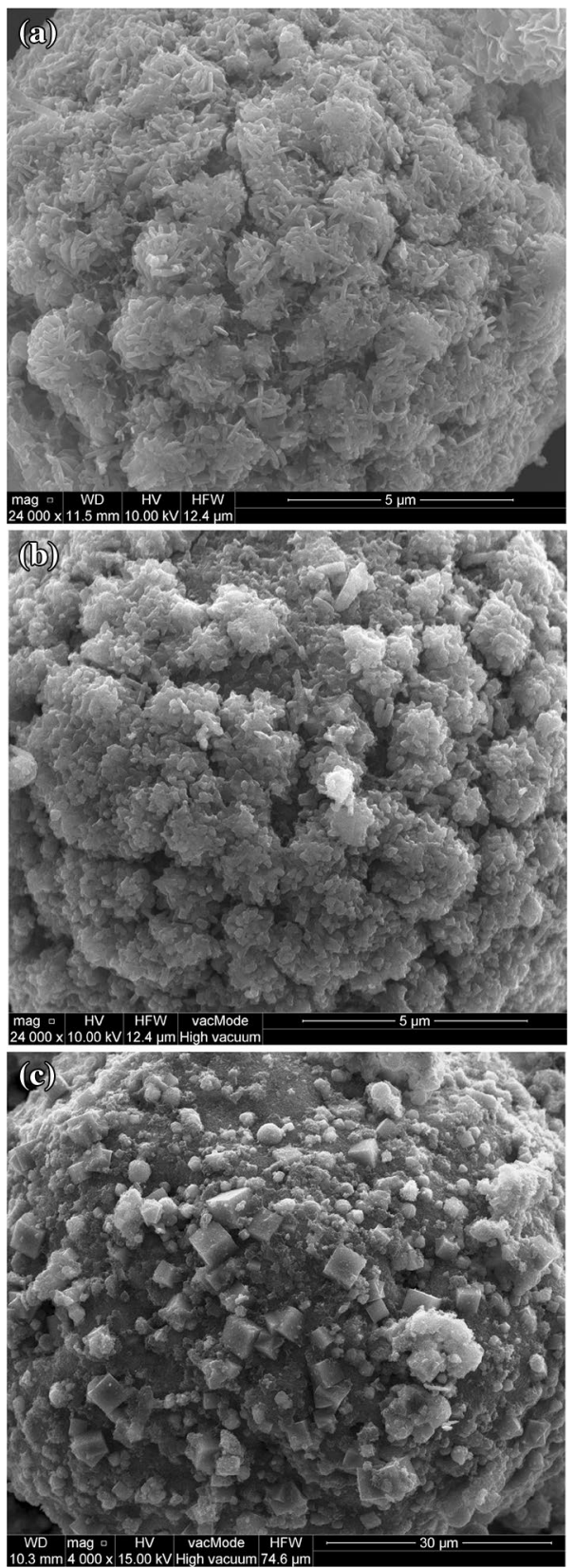

Fig. 1 SEM images of zeolites: a sodalite, b Na-P1, c Na-A

The solid surface charge density $\left(\sigma_{0}\right)$ changes as a function of solution $\mathrm{pH}$ for all examined zeolites without and with adsorbed poly(vinyl alcohol) are shown in Fig. 2. These results enable determination of $\mathrm{pH}$ values corresponding to the points of zero charge (pzc) of the studied systems. The $\mathrm{pH}_{\mathrm{pzc}}$ values of the used aluminosilicates without the polymer are as follows: for sodalite -10.65 , for Na-P1 zeolite -10.85 and for $\mathrm{Na}-\mathrm{A}$ zeolite -10.5 . This indicates that in the $\mathrm{pH}$ range below $\mathrm{pH}_{\mathrm{pzc}}$ the zeolite surface is endowed with a positive charge (reaching the maximum value of about $15 \mu \mathrm{C} / \mathrm{cm}^{2}$ ). Therefore in the whole range of $\mathrm{pH}(3-9)$, within which the PVA 

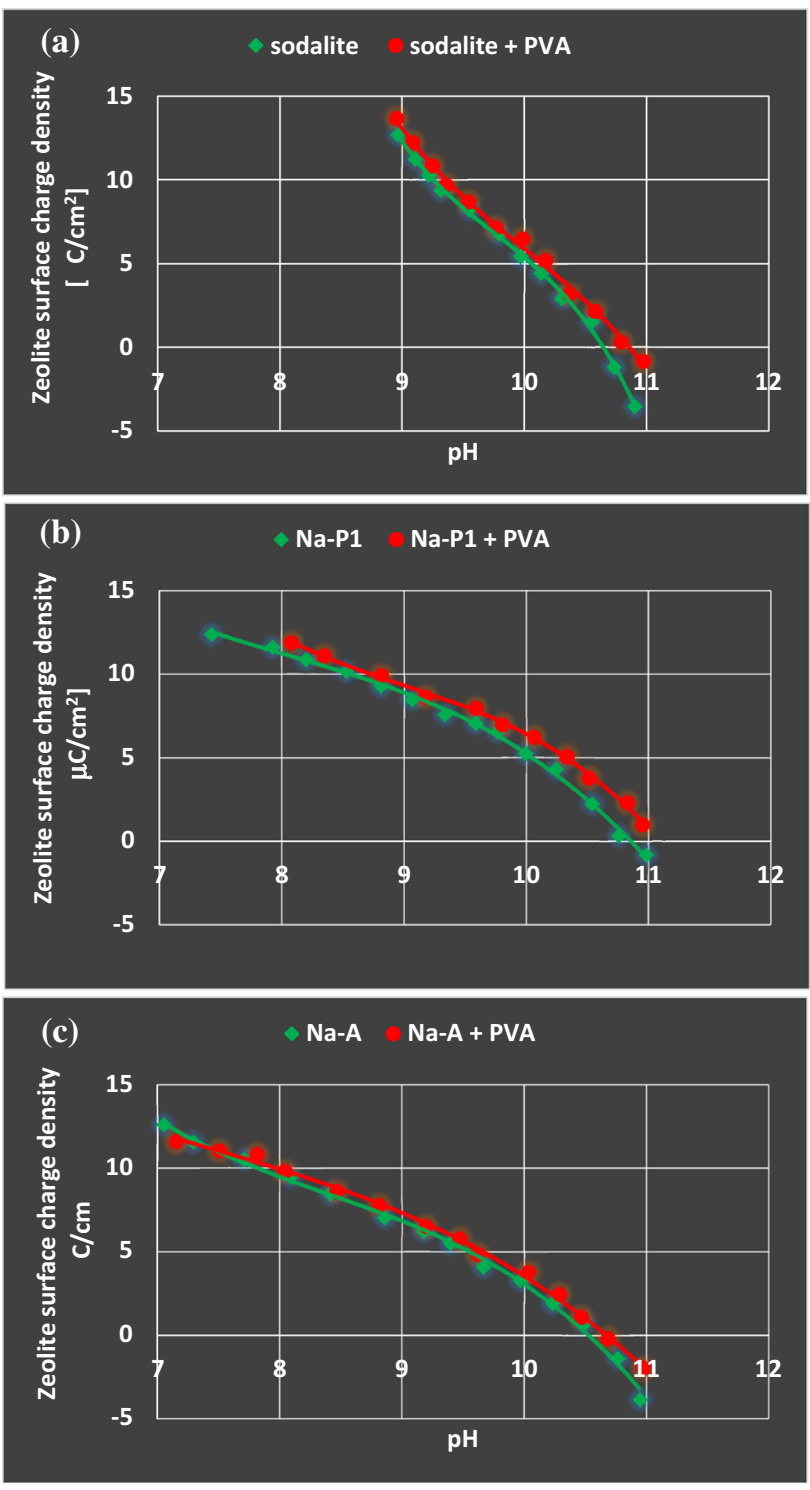

Fig. 2 Surface charge density of zeolites without and with adsorbed PVA: a sodalite, b Na-P1, c Na-A

adsorption was performed, there were favourable electrostatic conditions for binding of negatively charged PVA macromolecules on the positively charged zeolite surface.

The presence of the PVA adsorption layer causes a slight increase of the zeolite surface charge density and the inconsiderable shift of $\mathrm{pH}_{\mathrm{pzc}}$ position towards higher $\mathrm{pH}$ values. Undoubtedly, this is connected with the fact that the direct binding of negatively charged polymer segments with the solid active sites causes creation of an additional number of positively charged hydroxyl groups on the zeolite surface. The mechanism of this process can be represented by the schematic equation:

$$
\equiv S i(A l)-O H+P V A^{-}+H^{+} \rightarrow \equiv S i(A l)-O H_{2}^{+} P V A^{-}
$$

The $\equiv S i(A l)-O H$ represents the solid surface groups and $P V A^{-}$- the negatively charged polymer chains containing $14 \%$ of ionisable acetate groups.

Similar behaviour is typically observed for the aqueous suspensions of metal oxides in the presence of simple anions, molecules of dyes and surfactants of the anionic character (Skwarek et al. 2014; Wawrzkiewicz et al. 2015; Wiśniewska et al. 2018a). In the case of anionic polymers containing negatively charged groups connected with each segment in the macromolecule [e.g. poly(acrylic acid)], a significant decrease of the solid surface charge density in the polymer presence in comparison to the system without the macromolecular compound was observed (Chibowski and Wiśniewska 2001; Chibowski et al. 2010; Wiśniewska et al. 2017). In such a case the negative charges coming from numerous polymer functional groups accumulated in the by-surface layer of the solution and belonging to the adsorbed macromolecules were responsible for such interfacial behaviour.

The value of positive surface charge of zeolites at the specific $\mathrm{pH}$ values decides about the adsorbed amount of poly(vinyl alcohol) of the slight anionic character. The adsorption data presented in Fig. 3 point out to the noticeable increase in the PVA adsorption with the increasing $\mathrm{pH}$ of the solution. For all examined systems the adsorption experiments were performed at $\mathrm{pH} \mathrm{3,6}$ and 9, as well as at the initial polymer concentrations equal to 50,70,100 and $200 \mathrm{ppm}$. As mentioned above, in the whole examined $\mathrm{pH}$ range electrostatic attraction occurs between the positively charged zeolite surface and the negatively charged PVA chains. A slight increase in the amount of adsorbed polymer observed with the increasing solution $\mathrm{pH}$ results from the specific conformation of the polyalcohol chains in the surface layer. The density of positive surface charge of the zeolite decreases when the solution $\mathrm{pH}$ increases. Therefore the conformation of the adsorbed macromolecules becomes less and less flat. In the case of a larger number of positively charged surface groups of zeolite, the polymer macromolecule interacts with the adsorbent through the larger number of its negatively charged acetate groups. As a consequence, the adsorbed macromolecules "lying" flat on the surface cause blockade of the solid active sites. As the $\mathrm{pH}$ increases, the number of zeolite surface groups endowed with a positive charge decreases, which makes that the structure of the polymeric adsorption layer is more developed towards the bulk solution. This allows the adsorption of a larger number of PVA macromolecules on the surface unit of aluminosilicate, manifestation of which is a slight increase in polymer adsorption.

Additionally, in the whole range of studied $\mathrm{pH}$ the formation of hydrogen bonds between the polyalcohol functional groups and solid surface groups takes place. Both acetate (regardless of their ionization) and hydroxyl 

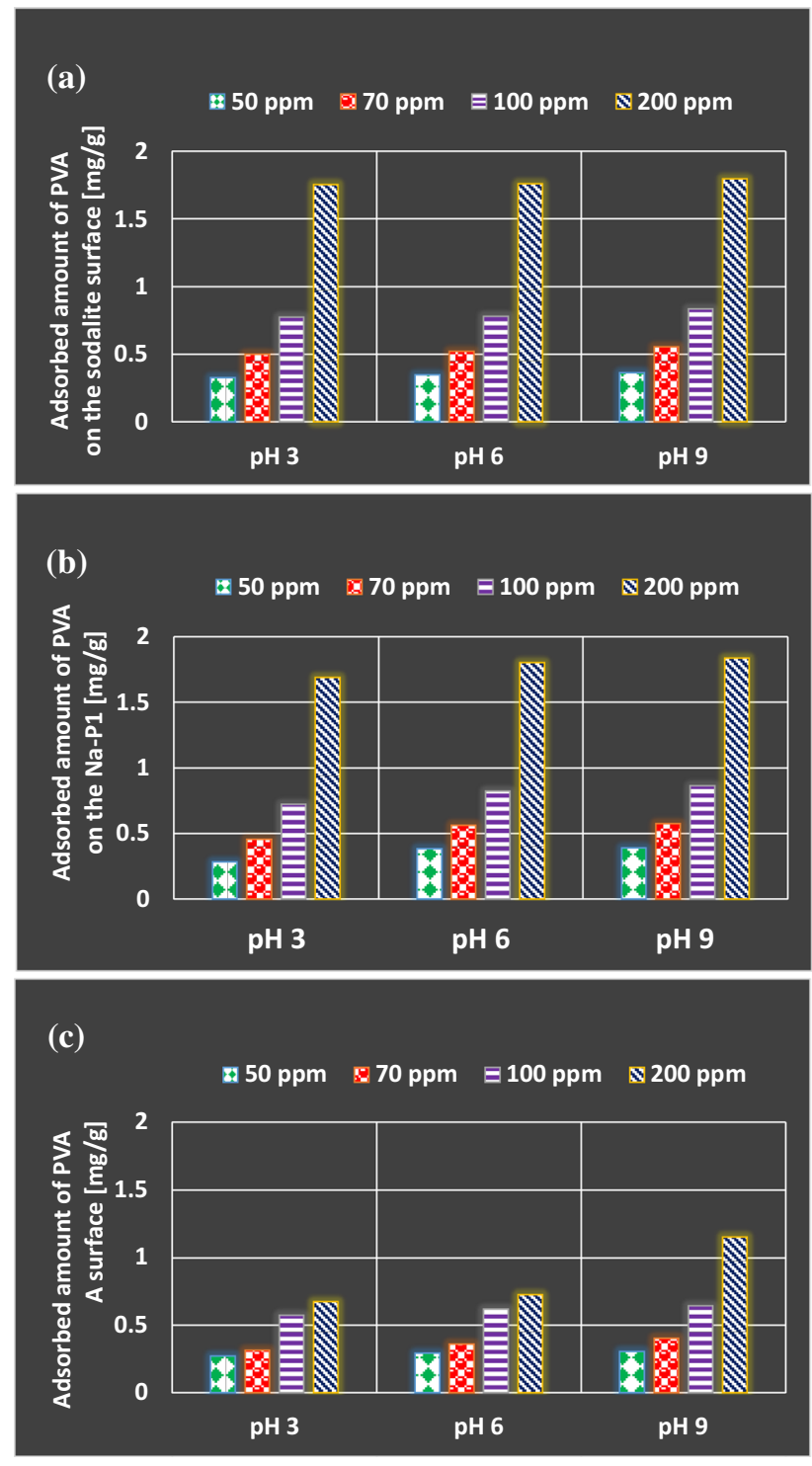

Fig. 3 Adsorbed amounts of PVA on the zeolites surface: a sodalite, b Na-P1, c Na-A obtained for various initial concentrations of the polymer

groups of the polymer can participate in these bonds creation. What is more, due to the fact that poly(vinyl alcohol) chains contain mainly segments with non-ionic hydroxyl groups the hydrophobic interactions can also be present in the examined systems.

In addition, for all examined zeolites an increase in the PVA adsorption with the increasing polymer concentration in the solution was obtained. This behaviour is rather typically observed in the case of adsorption of macromolecular compounds at the solid-solution interface, especially for the polymeric samples characterized by a certain polydispersity (Koopal 1981). In such a situation, removal of smaller molecular weight macromolecules by higher

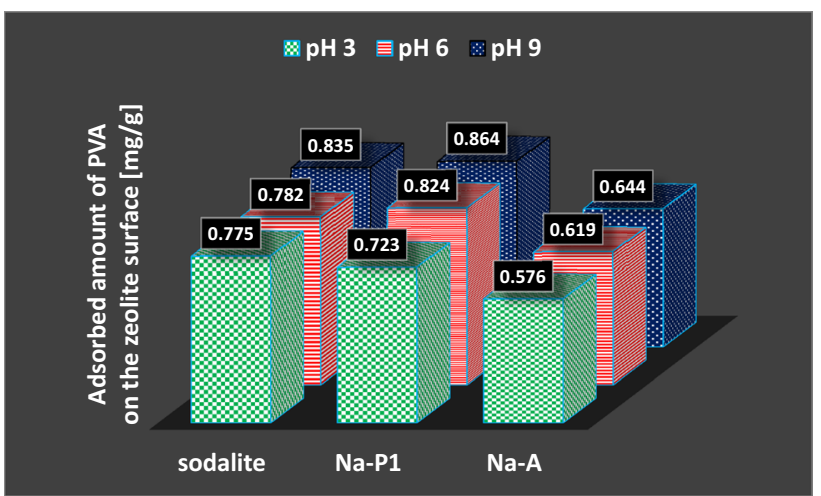

Fig. 4 Comparison of PVA adsorbed amount on the zeolites surface, initial concentration of PVA was $100 \mathrm{ppm}$

molecular weight ones plays an important role when the polymer concentration in the solution increases.

The adsorption capacity of zeolites in relation to poly(vinyl alcohol) depends also on the solid internal structure (Wiśniewska et al. 2018b). The comparison of the adsorbed amount of PVA on the surface of the examined zeolites obtained at the initial polymer concentration equal to $100 \mathrm{ppm}$ is shown in Fig. 4. The analysis of these data indicates that the comparable adsorbed amounts were obtained on the surfaces of sodalite and Na-P1 zeolite. The adsorption affinity of these solids for the PVA macromolecules is noticeably higher than that observed for Na-A zeolite. Undoubtedly, this is associated with a different porous structure of the applied zeolites. Na-A zeolite has the smallest average pore size $(7.3 \mathrm{~nm})$ of the all examined solids. The adsorption results suggest that the penetration of PVA macromolecules into the Na-A zeolite pores must be significantly reduced due to their size, and their adsorption occurs rather on the external surface of solid particles. On the other hand, sodalite contains pores with a larger mean diameter $(17.5 \mathrm{~nm})$ in its structure which enables more efficient penetration of polymer chains into their interior. As a result, the polymer amount adsorbed on the sodalite surface is higher.

The PVA adsorption influences not only the surface charge density of the examined zeolites, but also the charges located in the slipping plane area around the solid particles which is evidenced by the changes in the zeta potential values as a function of the solution $\mathrm{pH}$ in the poly(vinyl alcohol) presence (Fig. 5). The isoelectric points (iep) of solid suspensions (at which the concentrations of negatively and positively charged chemical individuals in the slipping plane area are the same) without the polymer are found at much lower $\mathrm{pH}$ values than the corresponding points of zero charge. The $\mathrm{pH}_{\text {iep }}$ values are as follows: for sodalite -5.2 , for Na-P1 zeolite -3.6 and for Na-A zeolite -4.8 . Such differences can be a result of electrical double layers overlapping formed on the opposite walls of solid pores, especially 

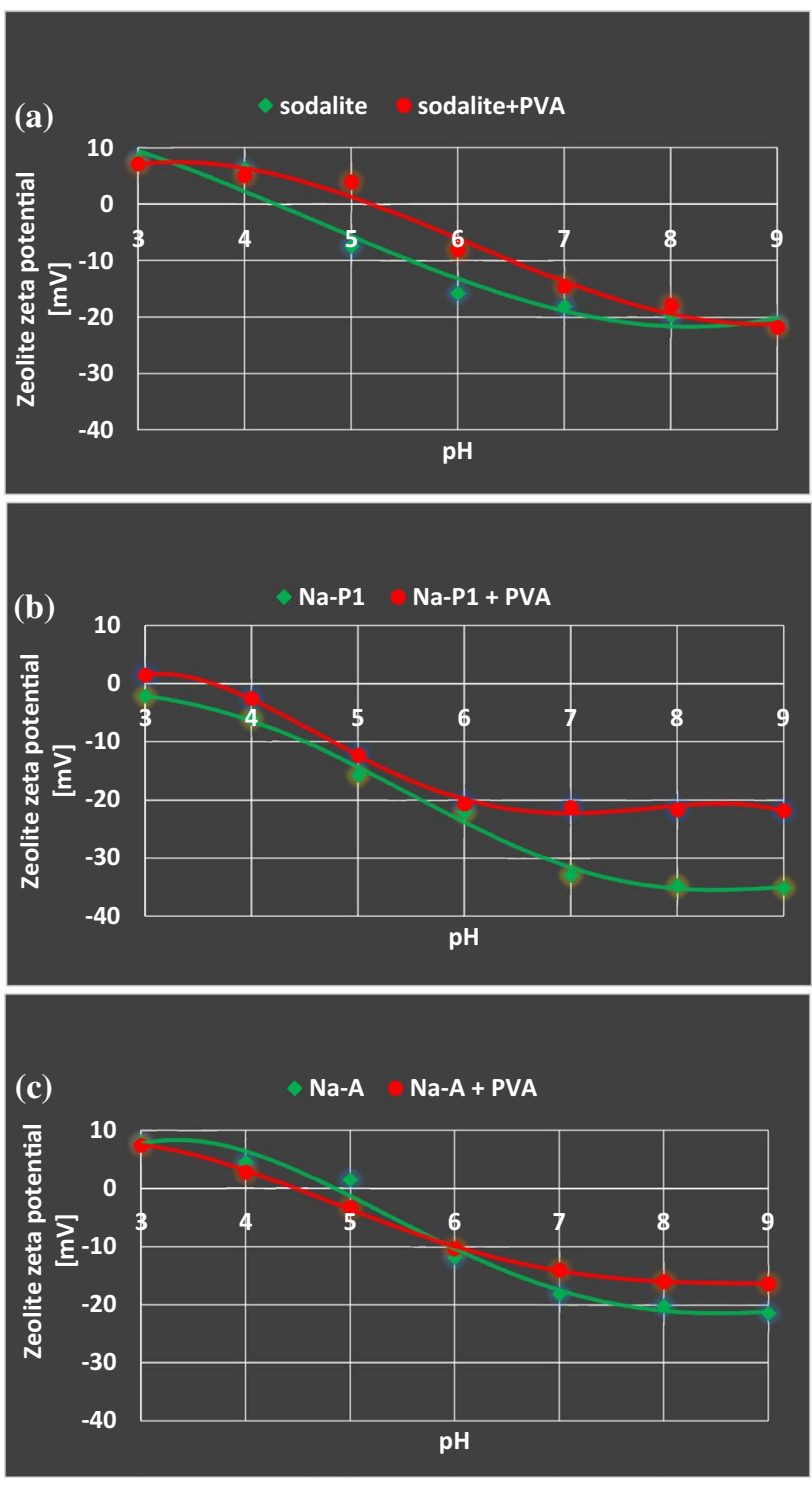

Fig. 5 Zeta potential of zeolites particles without and covered with PVA adsorption layers: a sodalite, b Na-P1, c Na-A

micropores (Skwarek et al. 2017). For sodalite and Na-P1 zeolite, the increase of the zeta potential is observed almost in the whole examined $\mathrm{pH}$ range in the polymer presence. In the case of $\mathrm{Na}-\mathrm{A}$ zeolite in the $\mathrm{pH}$ range below six there is a slight reduction in the zeta potential of solid particles coated with polymeric films. After the polyalcohol addition the changes in electrokinetic properties of zeolites are complex and they are a result of three effects accompanying the macromolecules adsorption: the slipping plane shift, the presence of charged functional groups of the polymer in the area of the slipping plane as well as the blockade of adsorption sites by polymer chains leading to their unavailability for other macromolecules (M'Pandou and Siffert 1987). The contribution of these effects determines the measured value of electrophoretic mobility (and also zeta potential) of the solid particles dispersed in the liquid medium.

\section{Conclusions}

The obtained results indicate that the modification of the surface of the examined zeolites (sodalite, Na-P1 and Na-A) by adsorption of poly(vinyl alcohol) contributes to the changes in their interfacial and electrokinetic properties which depends not only on the solution $\mathrm{pH}$ but also on the zeolite structure. Despite the favourable electrostatic conditions in the whole examined $\mathrm{pH}$ range (3-9), the greatest adsorbed amount of PVA on the zeolite surface was obtained at $\mathrm{pH}$ 9, at which the conformation of adsorbed macromolecules is the most extended towards the bulk solution. Additionally, the smallest amount of the adsorbed polymer was observed for Na-A zeolite which was characterized by the smallest average pore diameter. In such a case the penetration of macromolecules into the pores interior was significantly reduced. The hydrogen bonds and the hydrophobic interactions between the adsorbate and the adsorbent also participate in polymer binding with the solid surface. The addition of poly(vinyl alcohol) of slight anionic character to the zeolite suspension caused changes in the structure of the electrical double layer formed on the zeolite surface which was manifested in changes of the surface charge density and the zeta potential of solid particles.

Open Access This article is distributed under the terms of the Creative Commons Attribution 4.0 International License (http://creativeco mmons.org/licenses/by/4.0/), which permits unrestricted use, distribution, and reproduction in any medium, provided you give appropriate credit to the original author(s) and the source, provide a link to the Creative Commons license, and indicate if changes were made.

\section{References}

Bandura, L., Panek, R., Rotko, M., Franus, W.: Synthetic zeolites from fly ash for an effective trapping of BTX in gas stream. Microporus Mesoporous Mater 223, 1-9 (2016)

Bandura, L.,. Kołodyńska, D., Franus, W.: Adsorption of BTX from aqueous solutions by Na-P1 zeolite obtained from fly ash. Process Saf. Environ. Prot. 109, 214-223 (2017)

Bukhari, S.S., Behin, J., Kazemian, H., Rohani, S.: Conversion of coal fly ash to zeolite utilizing microwave and ultrasound energies: a review. Fuel 140, 250-266 (2015)

Chałupnik, S., Franus, W., Wysocka, M., Gzyl, G.: Application of zeolites for radium removal from mine water. Environ. Sci. Pollut. Res. 2, 7900-7906 (2013)

Chibowski, S., Wiśniewska, M.: Study of the adsorption mechanism and the structure of adsorbed layers of polyelectrolyte at metal oxidesolution interface. Adsorp. Sci. Technol. 19, 409421 (2001) 
Chibowski, S., Wiśniewska, M., Urban, T.: Influence of solution $\mathrm{pH}$ on stability of aluminum oxide suspension in presence of polyacrylic acid. Adsorption. 16, 321-332 (2010)

Derkowski, A., Franus, W., Beran, E., Czímerová A.: Properties and potential applications of zeolitic materials produced from fly ash using simple method of synthesis. Powder Technol. 166, 47-54 (2006)

Franczyk, J., Garbulewski, K.: Evaluation of zeolites and mixtures as reactive materials protecting groundwater at waste disposal sites. J. Environ. Sci. 25(9), 1764-1772 (2013)

Franus, W., Wdowin, M.: Removal of ammonium ions byselected natural and synthetic zeolites. Gosp. Sur. Miner.: Miner. Res. Manag. 26, 133-148 (2010)

Franus, W., Wdowin, M.: Wykorzystanie popiołów lotnych klasy F do produkcji materiału zeolitowego na skalę półtechniczną. Polityka Energetyczna. 14(2), 79-91 (2011)

Franus, W., Wdowin, M., Franus, M.: Synthesis and characterization of zeolites prepared from industrial fly ash. Environ. Monit. Assess. 186, 5721-5729 (2014)

Franus, M., Wdowin, M., Bandura, L., Franus, W.: Removal of environmental pollutions using zeolites from fly ash: a review. Fresenius Environ. Bull. 24, 854-866 (2015)

Gun'ko, V.M., Mikhailova, I.V., Zarko, V.I., Gerashchenko, I.I., Guzenko, N.V., Janusz, W., Leboda, R., Chibowski, S.: Study of interaction of proteins with fumed silica in aqueous suspensions by adsorption and photon correlation spectroscopy methods. J. Colloid Interf. Sci. 260, 56-69 (2003)

Hunter, R.J.: Zeta potential in colloid science. Academic Press, New York (1981)

Janusz, W.: Electrical double layer at the metal oxide/electrolyte interface in interfacial forces and fields: theory and applications. in Decker M. (Ed.), Surfactant Science, vol. 85. Berlin, New York (1994)

Koopal, L.K.: The effect of polymer polydispersity on the adsorption isotherm. J. Colloid Interf. Sci. 83, 116-129 (1981)

Kunecki, P., Panek, R., Wdowin, M., Franus, W.: Synthesis of faujasite (FAU) and tschernichite (LTA) type zeolites as a potential direction of the development of lime Class $\mathrm{C}$ fly ash. Int. J. Min. Process. 166, 69-78 (2017)

Kyziol-Komosinska, J., Rosik-Dulewska, C., Franus, M., Antoszczyszyn-Szpicka, P., Czupiol, J., Krzyzewska, I.: Sorption capacities of the natural and synthetic zeolites forthe $\mathrm{Cu}(\mathrm{II})$ ions. Polish J. Environ. Stud. 24, 1111-1123 (2015)

M'Pandou, A., Siffert, B.: Polyethylene glycol adsorption at the $\mathrm{TiO}_{2}-$ $\mathrm{H}_{2} \mathrm{O}$ interface-distortion of ionic structure and shear plane position. Colloids Surf. A 24, 159-172 (1987)

Musyoka, N.M., Missengue, R., Kusisakana, M., Petrik, L.F.: Conversion of South African clays into high quality zeolites. Appl. Clay Sci. 97-98, 182-186 (2014)

Nagy, D.J.: Handbook of size exclusion chromatography and related techniques. Marcel Dekker, Inc., Switzerland, pp 267-290 (2004)

Panek, R., Wdowin, M., Bandura, L., Wisła-Walsh, E., Gara, P., Franus, W.: Changes in the textural parameters of fly ash-derived Na-P1 zeolite during compaction processes. Mineralogia 48, 3-22 (2017)

Querol, X., Moreno, N., Umana, J.C., Juan, R., Hernandez, E., Fernandez-Pereira, C., Ayora, C., Janssen, M., García-Mártinez, J., Linares-Solano, A., Cazorla-Amoros, D.: Application of zeolite materials synthesised from fly ash to the decontamination of wastewater and flue gas. J. Chem. Technol. Biotechnol. 77, 292$298(2002)$

Skwarek, E., Janusz, W., Sternik, D.: Adsorption of citrate ions on hydroxyapatite synthetized by various methods. J. Radioanal. Nucl. Chem. 299, 2027-2023 (2014)

Skwarek, E., Gładysz-Płaska, A., Bolbukh, Y.: Adsorption of uranyl ions at the nano-hydroxyapatite and its modification. Nanosc. Res. Lett. 12, 278 (2017)

Sprynskyy, M., Lebedynets, M., Terzyk, A.P., Kowalczyk, P., Namięsnik, J., Buszewski, B.: Ammonium sorption fromaqueous solutions by the natural zeolite transcarpathian clinoptilolite studied under dynamic conditions. J. Colloid Interface Sci. 284, 408-415 (2005)

Wawrzkiewicz, M., Wiśniewska, M., Gun'ko, V.M., Zarko, V.I.: Adsorptive removal of acid, reactive and direct dyes from aqueous solutions and wastewater using mixed silica-alumina oxide. Powder Technol. 278, 306-315 (2015)

Wdowin, M., Franus, W., Panek, R.: Preliminary results of usage possibilities of carbonate and zeolitic sorbents in $\mathrm{CO}_{2}$ capture. Fresenius Environ. Bull. 21(12), 3726-3734 (2012)

Wdowin, M., Franus, M., Panek, R., Bandura, L., Franus, W.: The conversion technology of fly ash into zeolites. Clean Technol. Environ. Policy 16, 1217-1223 (2014)

Wiśniewska, M., Nowicki, P., Bogatyrov, V.M., Nosal-Wiercińska, A., Pietrzak, R.: Comparison of adsorption properties of $\mathrm{Mg}_{\mathrm{x}} \mathrm{O}_{\mathrm{y}}-\mathrm{SiO}_{2}$ and $\mathrm{Zn}_{\mathrm{x}} \mathrm{O}_{\mathrm{y}}-\mathrm{SiO}_{2}$ in the mixed oxide-poly(vinyl alcohol) system. Colloids Surf. A 492, 12-18 (2016)

Wiśniewska, M., Nowicki, P., Nosal-Wiercińska, A., Pietrzak, R., SzewczukKarpisz, K., Ostolska, I., Sternik, D.: Adsorption of poly(acrylic acid) on the surface of microporous activated carbon obtained from cherry stones. Colloids Surf. A 514, 137-145 (2017)

Wiśniewska, M., Fijałkowska, G., Szewczuk-Karpisz, K.: The mechanism of anionic polyacrylamide adsorption on the montmorillonite surface in the presence of $\mathrm{Cr}(\mathrm{VI})$ ions. Chemosphere. 211, 524-534 (2018a)

Wiśniewska, M., Fijałkowska, G., Ostolska, I., Franus, W., NosalWiercińska, A., Tomaszewska, B., Goscianska, J., Wójcik, G.: Investigations of the possibility of lithium acquisition from geothermal water using natural and synthetic zeolites applying poly(acrylic acid). J. Clean. Prod. 195, 821-830 (2018b)

Woszczuk, A., Franus, W.: A review of the application of zeolite materials in warm mix asphalt technologies. App. Sci. 7, 293 (2017)

Zhang, J.H., Yue, M.B., Wang, X.N., Qin, D.: Synthesis of nanosized TS-1 zeolites through solid transformation methodwith unprecedented low usage of tetrapropylammoniumhydroxide. Microporous Mesoporous Mater. 217, 96-101 (2015)

Zwick, M.M.: Poly(vinyl alcohol)-iodine complexes. J. Appl. Polym. Sci. 9, 2393-2424 (1965)

Publisher's Note Springer Nature remains neutral with regard to jurisdictional claims in published maps and institutional affiliations. 